\title{
An experimental model to retraining in microvascular suture ${ }^{1}$
}

\author{
Marcos Ricardo de Oliveira Jaeger ${ }^{\mathrm{I}}$, Pedro Bins Ely ${ }^{\mathrm{II}}$, Jefferson André Pires ${ }^{\mathrm{II}}$, Lydia Masako Ferreira ${ }^{\mathrm{IV}}$
}

DOI: http://dx.doi.org/10.1590/S0102-86502014001400001

IFellow Postdoc degree, Postgraduate Program in Plastic Surgery, Paulista School of Medicine, Federal University of São Paulo (UNIFESP-EPM), Brazil. Instructor of Departament of Plastic surgery, Santa Casa of Porto Alegre, Brazil. Conception, design, intellectual and scientific content of the study. IIPhD, Associate Professor, Division of Plastic Surgery, Federal University of Health Science, Surgeon-in-chief of Division of Plastic Surgery, Santa Casa of the Porto Alegre, Brazil. Manuscript writing, critical revision.

IIIMD. Resident, Department of Surgery, Federal University of Pelotas, Brazil. Member of Brazilian College of Surgeons, Brazil. Manuscript writing, critical revision.

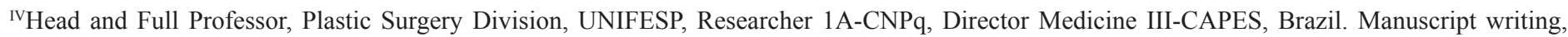
critical revision.

\section{ABSTRACT}

PURPOSE: To demonstrate an experimental model of up to four hours a week of independent study that allows relearning in microvascular sutures.

METHODS: Wistar rats between 200 and 500 grams surplus research experiments were used. Femoral vessels are covered on one or both sides through a groin incision obliquely along the inguinal ligament. Femoral artery and vein are isolated and measured being clamped and cut. The individual performs in microvascular anastomosis complexity arterial and venous terminoterminal sequence. terminolateral and venous and arterial grafts in vessels. Permeability is evaluated by testing vascular patency after creation of microvascular anastomosis.

RESULTS: In the first specimen, only arterial and venous vascular anastomosis are performed terminoterminal. The average diameter of the femoral veins varies from 0.8 to $2 \mathrm{~mm}$ between rodents (artery, between 0.6 and $1.4 \mathrm{~mm}$, between 0.8 and $2 \mathrm{~mm}$ vein). The superficiality of the vessels allows faster dissection, may also be held in other inguinal region.

CONCLUSION: The model of individual retraining allows learning microvascular suture in individuals of permanent staff. Key words: Animal model. Mycrosurgery. Rats. 


\section{Introduction}

The successful training in Plastic Surgery implies the development of microsurgical skills. Trainees in Plastic Surgery must nowadays dominate several aspects related to microsurgery, including the confection of microvascular anastomosis, so that they can carry out many surgical activities developed during the current programs of residency and fellowships in Plastic Surgery. In several centers, training in Microsurgery is offered as part of the residency program in general and plastic surgery ${ }^{1}$.

The purpose of this report is to show that a simple, cost-effective method, based in a 4-hour weekly program of independent study in the microsurgical laboratory, may allow the trainee and retraining to perform different types of microvascular anastomosis.

\section{Methods}

The protocol utilized in this experiment was previously approved by the Animal Care Committee of the Elizabeth Mac Master Research Building, University of Toronto, that facilitates the training of house staff and students in micro vascular anastomosis, and included a training model for micro vascular anastomosis end-to-end arterial, end-to-end venous, end-to-side arterial/ venous, and vein and arterial grafts. The trainee involved in this research was submitted to a class session explaining methods of handling rodents while working in the Animal laboratory. Rats utilized to this experiment were those considered as belonging to an exceeding population not to be used in other experiments.

We decided to divide the protocol in two sections, in which the trainee initially would only perform end-to-end arterial and, after completing successfully the arterial anastomosis, he could proceed with the end-to-end venous anastomosis. The second part of the protocol, in which the trainee would be required to perform end-to-side arterial and venous, as well as vein and arterial grafts, is to be started after the successful completion of the first part of the protocol.

In the period from April 32003 to June 162003, six Wistar rats weighting from 200 to $500 \mathrm{~g}$ underwent end-to-end arterial and venous anastomosis at the Elisabeth Mac Master Research Building. Specimens selected for the experiment were deprived of food and water 8 hours prior to the administration of anesthetics. Anesthesia consisted of a solution of Pentobarbital (Somolol ${ }^{\circledR}$ ) in a dosage of $60 \mathrm{mg} / \mathrm{kg}$, given intraperitoneally (Table 1). Sedation was obtained after 20 to 40 minutes. The operative site was then shaved bilaterally at the inguinal regions, and the rat was brought to the operative room. Rats were not entubated for the surgical procedure, rather being allowed to ventilate environmental air, but with supplemental oxygen at a rate of 1liter/minute (Table 2).

TABLE 1 - Injectable anesthetic agents and doses for adult rodents*.

\begin{tabular}{|c|c|c|c|c|}
\hline Anesthetic drugs & $\begin{array}{l}\text { Rodent } \\
\text { species }\end{array}$ & $\begin{array}{l}\text { Drug dose } \\
(\mathrm{mg} / \mathrm{kg})\end{array}$ & Route ** & $\begin{array}{l}\text { Duration } \\
\text { (minutes) }\end{array}$ \\
\hline $\begin{array}{c}\text { Ketamine/ } \\
\text { Xylazine } \\
\text { Acetopromazine }\end{array}$ & Rat & $50 / 5 / 1$ & IM, IP & $20-40$ \\
\hline $\begin{array}{l}\text { Ketamine/ } \\
\text { Xylazine }\end{array}$ & Rat & $\begin{array}{c}40-90 / \\
5-10 \\
\end{array}$ & IM, IP & $20-30$ \\
\hline $\begin{array}{l}\text { Pentobarbital } \\
(\text { Somolol } ®)\end{array}$ & Rat & $40-60$ & IP & $20-40$ \\
\hline $\begin{array}{c}\text { Fentanyl- } \\
\text { Fluanisone } \\
\text { (Hypnorm }{ }^{\circledR} \text { ) } \\
\text { and Diazepan }{ }^{\circledR}\end{array}$ & Rat & $\begin{array}{l}0.6 \mathrm{ml} / \mathrm{kg} \\
\text { and } 2.5\end{array}$ & IP & $20-40$ \\
\hline
\end{tabular}

*From the Elisabeth McMaster Research Building Animal Care Facilities Protocol for anesthesia of adult rodents.

**IM, intramuscular; IP, intraperironeal.

TABLE 2 - Acceptable protocol for inhalation anesthesia of adult rodents*

1. Phases of anesthesia include induction, maintainance and recovery

2. Materials required include a plexiglass rodent induction chamber (optional) and a rodent non-rebreathing anesthetic dircuit equipped with a proper gas scavenging system.

3. Inhalant anesthetic gases are safe for both ultra short $(<5$ minutes) and prolonged ( $>2$ hours) procedures.

4. Inhalation anaesthetics provid a quicker induction, more stable plane of surgical anesthesia, esier control of anesthetic depth and smoother recovery period than injectable anaesthetics.

5. Available inhalant gases: isoflurane, halothane.

6. Ensure proper scavenging of waste anesthetic gases, as chronic exposure can be detrimental to health.

7. Isoflurane provides more rapid induction and recovery phases, and causes less cardiopulmonary depression than halothane.

8. Excretion of inhalants is via lungs.

*From the Elisabeth McMaster Research Building Animal Care Facilities Protocol for anesthesia of adult rodents.

Specimen was positioned supine, with head placed to the left of the trainee. The femoral vessels were approached trough an inguinal oblique incision over the inguinal ligament, which allowed prompt identification of a fine layer of subcutaneous tissue 
covering the femoral vessels. Under microscope magnification, a coetaneous branch from the femoral vessels needs to be ligated to isolate the femoral artery and vein. Once isolated the femoral vessels, vein and artery were measured prior to confection of the anastomosis. Dissection should be carefully taken to the inguinal ligament, to achieve proper diameter to the anastomosis with 10-0 nylon. After artery and vein isolation, the vessels were clamped and sectioned. Raphy was undertaken under the microscope, usually consisting of 6 to eight stitches. Clamp was then released (Figures 1-4). Effectiveness of the anastomosis was evaluated by adequate flow throughout the vessel. Adequate flow was estimated, arbitrarily, at the following timings: immediately after releasing the clamp - time zero and 5 minutes and 30 minutes later. After evaluating adequate flow, the specimen was sacrificed. The method of disposal of the species involved in this study was anesthesia overdose.

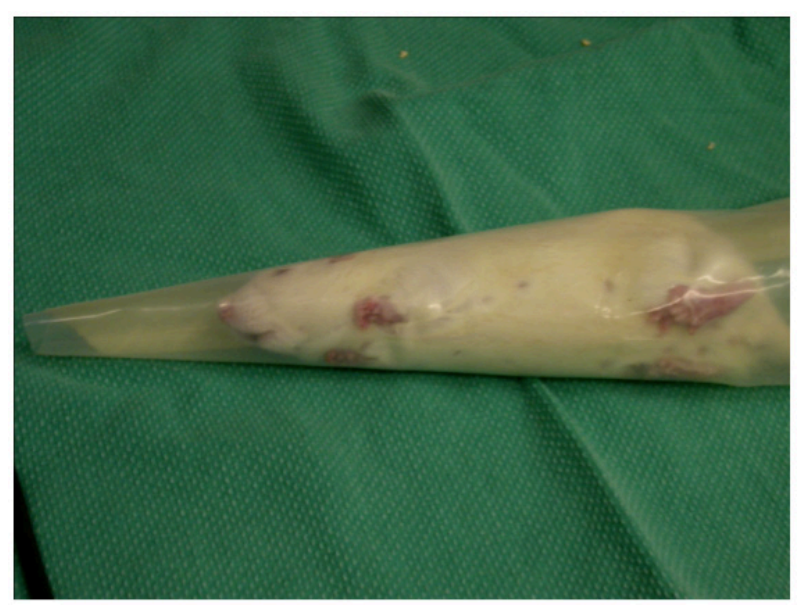

FIGURE 1 - Method for holding the rat.

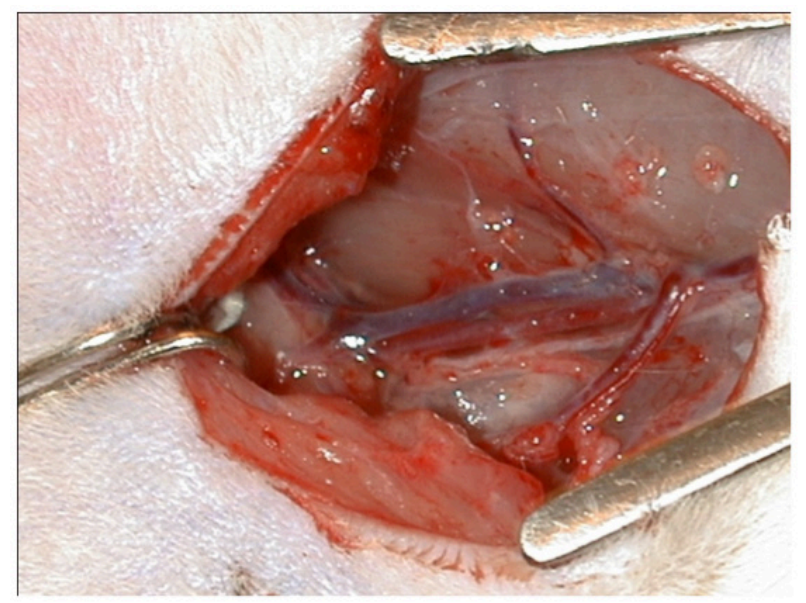

FIGURE 2 - Femoral vessels, artery and vein.

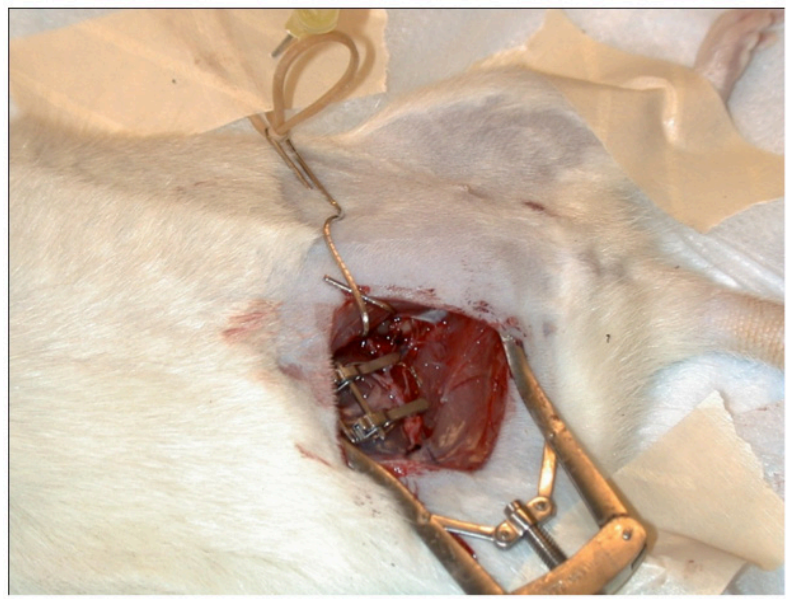

FIGURE 3 - Detail of the femoral artery, between microvascular clamps.

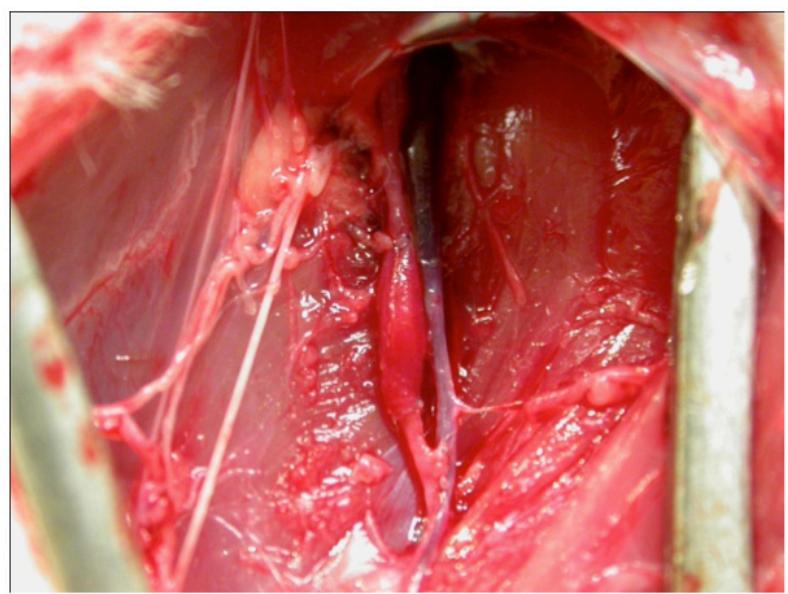

FIGURE 4 - Detail of a femoral vein in a graft between artery extremities cut.

\section{Results}

In the first specimen, only arterial and venous vascular anastomosis are performed terminoterminal. The average diameter of the femoral veins varies from 0.8 to $2 \mathrm{~mm}$ between rodents (artery, between 0.6 and $1.4 \mathrm{~mm}$, between 0.8 and $2 \mathrm{~mm}$ vein). The superficiality of the vessels allows faster dissection, and that dissection may also be held in the opposite inguinal region (Tables 3-5). 
TABLE 3 - Artery flow obtained instantaneously, 5 and 30 minutes later after releasing the microvascular clamp.

\begin{tabular}{|c|c|c|c|c|c|}
\hline Rat & $\begin{array}{c}\text { Weight } \\
(\mathrm{g})\end{array}$ & $\begin{array}{c}\text { Side } \\
\text { operated }\end{array}$ & $\begin{array}{l}\text { Flow at } \\
\text { time zero }\end{array}$ & $\begin{array}{l}\text { Flow after } \\
5 \text { minutes }\end{array}$ & $\begin{array}{l}\text { Flow after } \\
30 \text { minutes }\end{array}$ \\
\hline 1 & 270 & $\mathrm{R}$ & Yes & Yes & No \\
\hline 2 & 280 & $\mathrm{R}$ & Yes & Yes & No \\
\hline \multirow{2}{*}{3} & \multirow{2}{*}{350} & $\mathrm{R}$ & Yes & Yes & No \\
\hline & & $\mathrm{L}$ & Yes & Yes & Yes \\
\hline \multirow[t]{2}{*}{4} & \multirow[t]{2}{*}{240} & $\mathrm{R}$ & Yes & No & No \\
\hline & & $\mathrm{L}$ & Yes & Yes & Yes \\
\hline 5 & 270 & $\mathrm{R}$ & $\mathrm{No}^{*}$ & Yes & No \\
\hline \multirow{3}{*}{6} & \multirow{3}{*}{230} & $\mathrm{~L}$ & Yes & Yes & Yes \\
\hline & & $\mathrm{R}$ & Yes & Yes & No \\
\hline & & $\mathrm{L}$ & Yes & Yes & Yes \\
\hline \multirow[t]{2}{*}{7} & 400 & $\mathrm{R}$ & Yes & Yes & Yes \\
\hline & & $\mathrm{L}$ & Yes & Yes & Yes \\
\hline \multirow[t]{2}{*}{8} & 350 & $\mathrm{R}$ & Yes & Yes & Yes \\
\hline & & $\mathrm{L}$ & Yes & Yes & Yes \\
\hline \multirow[t]{2}{*}{9} & & $\mathrm{R}$ & Yes & Yes & $?$ \\
\hline & & $\mathrm{L}$ & Yes & Yes & Yes \\
\hline 10 & & $\mathrm{R}$ & Yes & Yes & Yes \\
\hline
\end{tabular}

* measurement before stripping

TABLE 4 - Venous flow obtained instantaneously, 5 and 30 minutes later after releasing the microvascular clamp.

\begin{tabular}{|c|c|c|c|c|c|c|}
\hline Rat & $\begin{array}{c}\text { Weight } \\
(\mathrm{mg})\end{array}$ & $\begin{array}{c}\text { Diameter } \\
\text { of vessels } \\
(\mathrm{mm})\end{array}$ & $\begin{array}{c}\text { Side } \\
\text { operated }\end{array}$ & $\begin{array}{c}\text { Flow } \\
\text { at time } \\
\text { zero }\end{array}$ & $\begin{array}{c}\text { Flow } \\
\text { after } 5 \\
\text { minutes }\end{array}$ & $\begin{array}{c}\text { Flow } \\
\text { after } 30 \\
\text { minutes }\end{array}$ \\
\hline 1 & 270 & 1.5 & & & & \\
\hline \multirow{2}{*}{2} & \multirow{2}{*}{280} & \multirow{2}{*}{1.9} & $\mathrm{R}$ & No & No & No \\
\hline & & & $\mathrm{L}$ & Yes & No & No \\
\hline \multirow[t]{2}{*}{3} & \multirow[t]{2}{*}{350} & \multirow[t]{2}{*}{2} & $\mathrm{R}$ & Yes & Yes & No \\
\hline & & & $\mathrm{L}$ & Yes & Yes & No \\
\hline 4 & 240 & 1 & $\mathrm{R}$ & Yes & No & No \\
\hline 5 & 270 & 1.8 & $\mathrm{~L}$ & Yes & Yes & Yes \\
\hline 6 & 230 & 1 & & & & \\
\hline \multirow[t]{2}{*}{7} & 400 & 1.2 & $\mathrm{R}$ & No & No & No \\
\hline & & 1.8 & $\mathrm{~L}$ & Yes & Yes & Yes \\
\hline \multirow[t]{2}{*}{8} & 350 & 1.2 & $\mathrm{R}$ & Yes & No & No \\
\hline & & 1.0 & $\mathrm{~L}$ & Yes & Yes & Yes \\
\hline \multirow[t]{2}{*}{9} & & .9 & $\mathrm{R}$ & Yes & Yes & No \\
\hline & & .8 & $\mathrm{~L}$ & Yes & Yes & Yes \\
\hline 10 & & .9 & $\mathrm{R}$ & Yes & Yes & Yes \\
\hline
\end{tabular}

* Usual 8 stitches per vein. Expected evolution after successfull vein anastomosis.
TABLE 5 - Artery flow with vein graft obtained instantaneously, 5 and 30 minutes later after releasing the microvascular clamp.

\begin{tabular}{|c|c|c|c|c|c|c|}
\hline Rat & $\begin{array}{c}\text { Weight } \\
(\mathrm{mg})\end{array}$ & $\begin{array}{c}\text { Artery } \\
\text { diameter } \\
(\mathrm{mm})\end{array}$ & $\begin{array}{c}\text { Vein } \\
\text { graft } \\
\text { diameter } \\
(\mathrm{mm})\end{array}$ & $\begin{array}{c}\text { Flow } \\
\text { at } \\
\text { time } \\
\text { zero }\end{array}$ & $\begin{array}{c}\text { Flow } \\
\text { after 5 } \\
\text { minutes }\end{array}$ & $\begin{array}{c}\text { Flow } \\
\text { after 30 } \\
\text { minutes }\end{array}$ \\
\hline 11 & 340 & .7 & 1.1 & No & No & No \\
\hline 12 & 350 & .8 & $.3 \times 1.2$ & $?$ & Low & No \\
\hline 13 & 360 & .8 & 1.4 & Yes & Yes & No \\
\hline 14 & 350 & .7 & 1.4 & Yes & No & No \\
\hline 15 & 450 & .9 & 1.4 & Yes & Yes & Yes \\
\hline 16 & 400 & .9 & 1.0 & Yes & Yes & Yes \\
\hline
\end{tabular}

* Expected evolution after successfull vein anastomosis.

\section{Discussion}

In the past, plastic surgeons have seen their field not only grow in numbers but also in caseload and clinical possibilities of utilization of microsurgery. As a result, trainees and staff in plastic surgery are nowadays required to pursue abilities in basic microsurgical procedures and clinical indications. However, the maintenance of a well trained transitory or permanent staff may require, from time to time, initiating courses or periodic retraining of microvascular surgery ${ }^{2,3}$

The protocol utilized in the present study was previously approved by the Elisabeth Mac Master Research Building Animal Care Committee on April 17, 2002, and was initially designed as a Training Model for Microvascular Anastomosis. Rationale for the usage of this protocol was made on the excellent size match with respect to human digital vessels for replantation, the excellent exposure allowed for training, and the immediate effects of repairs for scrutiny, evaluation learning and improvement. As part of the routine at the Elisabeth Mac Master Research Building, trainees involved in experimental protocols go through a training session that lasts approximately 3 hours prior to have access to the experimental laboratory. This is especially important so that the trainee can handle animal species safely and following the ethics protocols of experimental research. In fact, many trainees are already used to the handling of small animal specimens due to previous courses or academic activities at the time of Medical School.

Many non animal models have been in use for training of microsurgical skills, including rubber glove material, placenta, colored beads, microsilicone tubing, leaves, etc. Expenses and the increasingly strict regulations towards the utilization of live specimens have justified their use. However, the rat femoral vessels include not only the adventitial stripping as a standard procedure before a microvascular anatomosis, but also instruct the beginner on tissue handling. Those steps are hardly reproduced in non-animal 
models (see Mubin). The necessity of learning on tissue handling becomes more obvious when we perceive how hard the venous anastomosis to the beginner is in comparison to the arterial.

The utilization of the femoral vessels also allows the trainee to experience a sensation close to digit replantation, a common procedure to many plastic surgeons not necessarily involved in microsurgery in their daily hospital activities. The rat femoral vessels diameters are from .6 to $1 \mathrm{~mm}$ to the artery - , and 1 to $2 \mathrm{~mm}$ to the vein. Other advantage of the femoral vessels is the possibility to evaluate flow after the confection of the anastomosis. In the present study, we took into consideration three different times to evaluate flow: immediately after releasing the clamp, five minutes later, and after half-an-hour. We evaluated flow at those times to estimate, in the case of failure, the probable reason. Common reasons were stitching the posterior vessels wall, incorrect adventitia stripping generating the common thrombogenic effect, and other technical reasons ${ }^{5-7}$.

One of the problems with an independent study is the necessity of adequately perform all pre-operative steps and anaesthesia induction prior to the surgical procedure. Trainees must also know basic techniques of handling small rodents. At the Elisabeth McMaster Research Building, all trainees are submitted to a training session prior to initiate any activities in the laboratory. During the first weeks, the trainee will need guidance on a daily basis to adjust the routines of the research laboratory. With the assigned staff surgeon away it is important that the trainee be able to construct a friendly environment in which the laboratory technicians feel complimentary to behave in a supportive way ${ }^{8}$.

Although infrequent it may happen that unsupervised trainee becomes unproductive. So it is necessary to assess periodically the development of the trainees' skills in the laboratory. This can be done through informal presentations to the assigned staff surgeon or program director, or throughout formal reports that could be presented during the regular round activities ${ }^{9}$.

The experience in the research facility is far more rewarding than only an opportunity to improve the microsurgical skills. Many trainees will have the opportunity to apply their knowledge in future projects in their own countries, and the participation in the Research Laboratory Activities will allow the trainee to be initiated in the atmosphere of a research center ${ }^{1,10}$.

Another common problem with microsurgery training facilities is the cost. In order to maintain trained personal and perpetuate research funding, the existence of a research laboratory with microsurgical facilities is justifiable and should be granted. The large financial portfolio necessary to maintain the training and research laboratory may be achieved trough grants, clinical studies, ongoing training and facility use fees, or departmental or endowment funds. In the periods of financial shortage, new financial possibilities are to be thought. At present, Sprague-Jawley rats fee for utilization is $\$ 20$, each. This amount should be added to the operative time in the research operative room, cost of anesthetics and microsurgical supplies. The utilization of the exceeding population of rats, common at research facilities of great ongoing research from times to times, may give the provider some relief to reduce costs substantially ${ }^{1,11,12}$.

\section{Conclusion}

The training model presented permiteed the possibility of individual retraining in microsurgery. The weekly training time is short and low cost.

\section{References}

1. Livingston CK, Ruiz-Razura A, Cohen BE. Guidelines for a successful microsurgery training center and research fellowship. Plast Reconstr Surg. 1999 Oct;104(5):1555-8.

2. Mubin H, Tosun Z, Savaci N. A non-animal model for microsurgical training with adventitial stripping. Plast Reconstr Surg. 2000 Sept.;106(4):958-9.

3. Wanzel KR, Madsumoto ED. Teaching technical skills: training on a simple, inexpensive and portable model. Plast Reconstr Surg. 2002 Jan;109(1):258-63.

4. Rohrich RJ, Robinson JB, Adams WP. The Plastic Surgery Research Fellow: revitalizing an important asset. Plast Reconstr Surg. 1998 Sept;102(3):895-8.

5. Pshenisnov KP, Bessononv SN. Operation Smile and its help in the development of Plastic and Reconstructive Surgery in Russia. Plast Reconstr Surg. 1999 Oct;104(5):1569-70.

6. Noone RB, Noone BR. Beyond competence. Plast Reconstr Surg. 2002 Jan;109(1):372-9.

7. Rohrich RJ. The making of a Plastic Surgeon: present and future. Plast Reconstr Surg. 2003 Mar;111(3):1289-90.

8. Butler PE. Assessing technical skills of plastic surgeons. Plast Reconstr Surg. 2003 Jan;111(1):491-2.

9. Fish JS, McKee NH. Survey of factors influencing the selection of academic plastic surgeons. Plast Reconstr Surg. 1998 Apr;101(5):1400-5.

10. Lapuerta L, Shayani P, Ruiz-Razura A. Long Term Clinical Experience with the Ruiz-Cohen Intraoperative arterial expanders. Plast Reconstr Surg. 2002 Mar;109(3):1123-7.

11. Gorman PJ, Mackay DR, Kutz RH, Banducci DR, Haluck RS. Video microsurgery: evaluation of a standard laparoscopic equipment for the practice of microsurgery. Plast Reconstr Surg. 2001 Sept 15;108(4):864-9.

12. Abraham V, Srinivasan J. Arteriovenous shunts. Plast Reconstr Surg. 1998 Jul;102(1):263-4.

\section{Correspondence:}

Dr. Marcos Jaeger

Rua Attilio Bilibio, 120/106

91530-008 Porto Alegre - RS Brasil

Fax: (55 51)3028-8738

marcosjaeger@hotmail.com

${ }^{1}$ Research performed at Microsurgery Research Laboratory Facility, Federal University of Heath Sciences of Porto Alegre (UFCSPA), Brazil. 